\title{
AN UNUSUAL DISTRIBUTION OF 4-SUBSTITUTED GLUTAMIC ACIDS IN SOPHORA JAPONICA
}

\author{
HARRY C. WINTER and Eugene E. DEKKer \\ Department of Biological Chemistry, The University of Michigan, Ann Arbor, MI 48109-0606, U.S.A.
}

(Received 10 February 1987)

Key Word Index-Sophora japonica; Leguminoseae; 4-substituted glutamic acids; 4-methyleneglutamic acid; 4 methyleneglutamine; 4-methylglutamic acid; 2-oxo-4-methylglutaric acid; transamination.

\begin{abstract}
High levels of 4-methyleneglutamine accumulate in the roots and leaves of Sophora japonica, but no detectable amounts of 4-methyleneglutamic acid and only trace quantities of 2-oxo-4-methyleneglutaric acid are seen. 4Methylglutamic acid, however, is present in leaves and roots at a level 5-25\% of that found for 4-methyleneglutamine; 2 ox0-4-methylglutaric acid is the most abundant keto acid detected in 28-day leaf extracts, but no 4-methylglutamine is seen. Transamination by pig heart glutamate: oxalacetate aminotransferase of the 2-oxo-4-methylglutaric acid that occurs in this species yields erythro-4-methylglutamic acid; the 2-oxo acid, therefore, has the $(4 R)$ configuration. The 4 methylglutamic acid isolated from this plant is also the erythro isomer and is probably of the $(2 S, 4 R)$ configuration. This is the first report of the presence of 4-substituted glutamic acids in Sophora and the first instance where high levels of 4 methyleneglutamine are present in the absence of detectable levels of 4 -methyleneglutamic acid.
\end{abstract}

\section{INTRODUCTION}

Various 4-substituted glutamic acids and their corresponding derivatives (i.e. the 2-oxo analogue and/or the $\gamma$-amide) accumulate in a wide variety of plant species, especially in members of the Leguminosae and Liliaceae [1]. Of such compounds, 4-methyleneglumatic acid (4 Meglu)* and its amide, 4-methyleneglutamine (4-Megln), appear to be most widespread. 4-Methylglutamic acid (4Mglu) and 4-hydroxy-4-methylglutamic acid are also found in several species either alone or together with 4Meglu and 4-Megln, and limited evidence suggests that these substituted amino acids may be metabolically interrelated $[2,3]$. In our efforts to elucidate biosynthetic and biodegradative pathways involving 4-Meglu (primarily in Arachis hypogaea), we examined its presence and the distribution of related compounds in several other legume species. We report here an unusual pattern of 4-substituted glutamic acids and amides in seedlings of the Japanese pagoda tree, Sophora japonica.

\section{RESULTS AND DISCUSSION}

Leaves ( $c a 0.5 \mathrm{~g}$ ) from a seedling grown in the greenhouse for six weeks were excised, frozen in liquid nitrogen within one hr, and stored at $-20^{\circ}$ for two weeks before being extracted. Analysis of these extracts on the amino acid analyser suggested the possible presence of two 4 . substituted glutamic acids - a major constituent eluted at

\footnotetext{
*Abbreviations: 4-Meglu, 4-methyleneglutamic acid; 4-Megln, 4-methyleneglutamine; 4-Mglu, 4-methylglutamic acid; $O M G, 2$. oxo-4-methylglutaric acid; OMeG, 2-oxo-4-methyleneglutaric acid; PTC, phenylthiocarbamyl; GOT, glutamate:oxalacetate aminotransferase.
}

the position of 4-Meglu or 4-Mglu and a minor component coeluted with 4-Megln. When the acidic amino acids were fractionated by thin layer chromatography on cellulose followed by reaction with ninhydrin, a purple spot of the correct mobility confirmed the presence of 4 Mglu but no yellow-brown spot characteristic of 4-Meglu was detected. The amino acid which eluted in small quantity at the position of Megln stayed in the neutral fraction and was not further characterized then. Essentially the same pattern was seen with extracts of emerging leaves as well as with mature leaves of mature plants, although emerging leaves contained considerably lesser amounts of these unusual amino acids compared to their content of asparagine, alanine, and other protein amino acids.

In all subsequent work, ungerminated seeds and seedlings up to eight weeks of age were extracted without prior freezing and storage. Such extracts of seedlings contained considerably greater amounts of the amino acid eluting at the position of 4-Megln and lesser amounts of 4-Mglu; neither of these two compounds was detected in extracts of ungerminated seds (Table 1). As can be seen, the level of 4-Megln is second only to aspartic acid; asparagine, glutamine, threonine and serine eluted as one peak in these analyses and the size of this combined peak was comparable to that for aspartic acid. $4 \mathrm{Mglu}$ was routinely detected in all samples analysed by cellulose TLC but 4 Meglu was not. When phenylthiocarbamyl (PTC)-amino acids were analysed by the pico-tag method [4], the PTCderivatives of L-glutamic acid and $1-4$-Meglu eluted at 1.87 and $2.08 \mathrm{~min}$, respectively, whereas the PTC. derivative of synthetically-prepared 4-Mglu (containing the erythro-DL and threo-DL diastereoisomers) eluted as nearly equal size peaks ( $3: 2$ ratio) at 2.23 and $2.42 \mathrm{~min}$. Direct analysis of the acidic amino acid fraction from 
Table 1. Levels of acidic amino acids present in Sophora japonica

\begin{tabular}{|c|c|c|c|c|c|c|c|c|}
\hline \multirow{3}{*}{$\begin{array}{l}\text { Amino } \\
\text { acid }\end{array}$} & \multicolumn{8}{|c|}{ Days of germination } \\
\hline & \multirow{2}{*}{$\frac{0}{(\text { seed })}$} & 4 & 7 & \multicolumn{2}{|c|}{14} & \multicolumn{2}{|c|}{28} & \multirow{2}{*}{$\frac{56}{\text { (leaf) }}$} \\
\hline & & (sex & & (lean) & (root) & (leaf) & (root) & \\
\hline $\begin{array}{l}\text { Aspartic } \\
\text { acid }\end{array}$ & trace & 18.0 & 474 & 77.9 & 567 & 68.0 & 1110 & 3.69 \\
\hline $\begin{array}{l}\text { Glutamic } \\
\text { acid }\end{array}$ & 4.43 & 6.53 & 29.2 & 2.55 & 3.35 & 5.1 & 11.3 & 1.83 \\
\hline 4-Megln & 0 & 0.65 & 54.1 & 58.8 & 113 & 38.6 & 20.7 & 21.0 \\
\hline 4-Mglu & 0 & 0.42 & 1.12 & 4.17 & 5.65 & 7.2 & 1.9 & 5.62 \\
\hline (4-Meglu) & & $0^{*}$ & of & $0^{*}$ & $0^{*}$ & $0+$ & $0+$ & 0 \\
\hline Alanine & 1.79 & 5.69 & 18.4 & 7.75 & 11.2 & 16.2 & 15.5 & 5.04 \\
\hline $\begin{array}{l}\text { 4-Amino } \\
\text { butyric acid }\end{array}$ & 2.50 & 1.49 & 11.2 & 28.4 & 28.9 & 35.6 & 18.4 & 13.9 \\
\hline
\end{tabular}

Values are expressed as $\mu \mathrm{mol} / \mathrm{g}$ dry wt of tissue, as determined by ion-exchange amino acid analysis. Values for 4-Mglu assume the absence of 4-Meglu, which was demonstrated qualitatively by the procedure indicated for each sample.

* None detected by TLC.

+ None detected by either TLC or by pico-tag analysis.

Sophora extracts as their PTC-derivatives showed only the peak at $2.23 \mathrm{~min}$ in an amount comparable to that determined by ion-exchange amino acid analysis; no peak corresponding to 4-Meglu (i.e. at $2.08 \mathrm{~min}$ ) was ever seen in samples examined by this method. On the other hand, the acidic amino acid fraction obtained after hydrolysis of the neutral amino acids contained 4-Meglu in an amount equal to that determined for 4-Megin in the original unhydrolysed sample. In such analyses, no 4-Mglu was detected either by TLC or pico-tag analyses indicating that no 4-methylglutamine (or other $\gamma$-glutamyl derivative) was present.

Although we did not isolate $4-\mathrm{Mglu}$ in sufficient quantity from $S$. japonica to be able to determine directly its configuration nor were any of the individual synthetically-prepared isomers available to us, the following indirect results suggest the natural plant amino acid is the erythro isomer. First, as noted earlier, syntheticallyprepared 4-Mglu is resolved into its two diastereoisomers by the pico-tag system and the product isolated from S.japonica coelutes with the faster-eluting diastereoisomer. Blake and Fowden [5] reported that erythro-4-Mglu cyclizes faster to the pyrrolidone when heated at $\mathrm{pH} 3$ than does the threo isomer. We found that on heating the mixture of synthetically prepared diastereoisomers under these conditions, the faster-eluting form disappears more rapidly (Fig. 1) suggesting that it is the erythro isomer. It was also observed that erythro-4 Mglu migrated more slowly than the threo isomer when subjected to paper chromatography in 2-methylbutan-2ol-acetic acid-water $(10: 1: 10)$ [5]. Using the same solvent system with cellulose TLC plates and three successive developments to improve the separation, we resolved synthetically prepared $4-\mathrm{Mglu}$ into its two diastereoisomers with apparent $R_{f}$ values of 0.45 and 0.49 . 4-Mglu isolated from $S$. japonica migrated with the lower $R_{f}$ value. Third, we applied the electrophoretic procedure of Przybylska and Strong [6] in which they found that erythro-4-Mglu migrated faster toward the anode at $\mathrm{pH}$ 4.4. For this purpose, we prepared 4-Mglu by limited

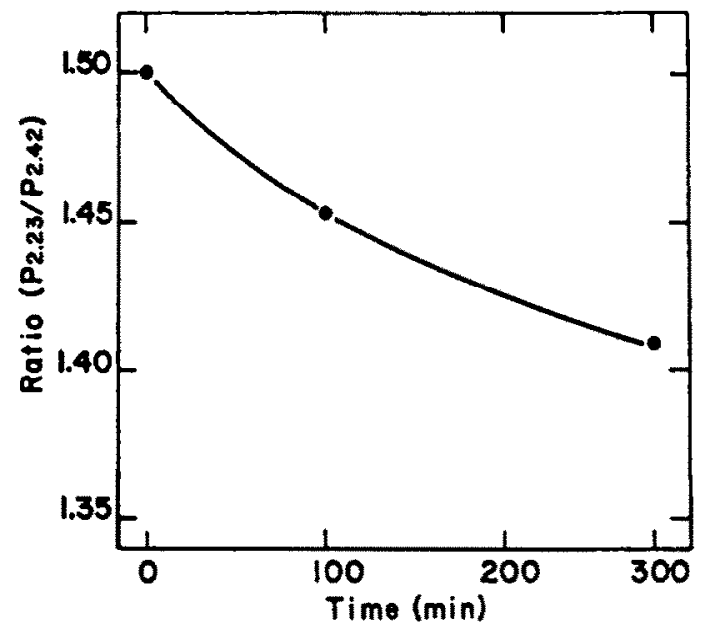

Fig. 1. Relative rate of loss of the fast- and slow-eluting isomers of 4-Mglu under conditions of cyclization to 3-methyl-5carboxypytrolidone. A solution (10 mM) of syntheticallyprepared 4-Mglu (erythro + threo isomers) was adjusted to $\mathrm{pH}$ 3.0 with acetic acid and heated to $70^{\circ}$. At the times indicated, $10 \mu \mathrm{l}$ samples were withdrawn, neutralized with triethylamine, dried, and the compounds present subjected to pico-tag derivatization and analysis. The ratio is that of the integrated area of the peak at $2.23 \mathrm{~min}$ (the erythro isomer) divided by that at $2.42 \mathrm{~min}$ (the threo isomer).

transamination of DL-2-oxo-4-methylglutaric acid (OMG) (see below) which sample contained only the faster-eluting isomer when subjected to pico-tag analysis and showed the faster electrophoretic mobility $\left(\boldsymbol{R}_{m}\right.$ value $=0.72-0.75$ versus $0.69-0.71$, relative to aspartic acid). Collectively, these results are consistent with 4 -Mglu from $S$. japonica being the erythro isomer. This finding contrasts with the accumulation of threo-4hydroxy-Lglutamic acid in leaves of Phlox decussata $[7,8]$. 
In these studies with $S$. japonica, we also examined the levels of 2-0xo acids in extracts of 28-day-old leaves and roots; this was done by high pressure liquid chromatography fractionation and characterization of their quinoxalinol derivatives. Derivatives of 2-oxoglutaric acid, pyruvic and/or oxalacetic acid, $O M G$, and an unknown acid (possibly 2-oxo-4-hydroxy-4-methylglutaric acid) were detected in leaves and roots (Table 2). In addition, a small peak at the position of 2-0x0-4-methyleneglutaric acid (OMeG) as well as several unidentified peaks of similar size were observed in extracts of leaves. A sample of leaf extract containing the 2-oxo acids was subjected to transamination by pig heart glutamate:oxalacetate aminotransferase (GOT); aspartate served as the amino group donor and the oxalacetate formed was reduced with NADH in the presence of malate dehydrogenase.t Any oxalacetate present in the original extract was removed by a prior incubation with the enzyme system in the absence of aspartate. The amount of NADH oxidized was found to correspond to the amount of OMG plus the trace of 2oxoglutarate known to be present in the sample; pyruvate was not expected to undergo transmination with GOT and whatever acids were present in the unknown fraction apparently were also not utilized as substrates in this system. Analysis of the products of the aminotransferase reaction by the pico-tag method showed that erythro-4 Mglu had been formed; no 4-Meglu was detected. Since only L-amino acids are utilized or made by pig heart GOT [9], the product formed by transamination of OMG must be $\mathrm{L}-(2 S, 4 R) 4-\mathrm{Mglu}$. Hence, OMG in the extracts is of the (4R) configuration and the naturally occurring $4-\mathrm{Mglu}$ is also most likely the $(2 S, 4 R)$-isomer.

To the best of our knowledge, the only route for 4 Megln biosynthesis is via amidation of 4-Meglu as catalysed by a highly specific 4-Megln synthetase [10]; trace amounts may possibly be formed by nonspecific action of glutamine synthetase [11]. Where and when they are found in biological tissues, 4-Meglu and 4-Megln most generally occur together (as is true for peanut and honeylocust plants). The results reported here for $S$. japonica are the first in our studies where 4-Megln is found in the absence of any detectable amount of $4 \mathrm{Meglu}$. If any 4 Meglu is actually present, its level is extremely low ( $<0.1 \mu \mathrm{mol} / \mathrm{g}$ dry wt of tissue) suggesting that either efficient coupling between 4-Meglu biosynthesis and amidation (possibly via an enzyme complex) occurs in this species or a different route exists in Sophora for 4-Megln formation. Be that as it may, the concept of 4-Meglu/4Megln serving as a coupled nitrogen-translocating system, as has been suggested for peanut plants $[10,12]$, would not seem to apply to $S$. japonica. What the physiological significance is of reasonable levels of OMG and erythro-4$\mathrm{Mglu}$ in $\mathrm{S}$. japonica also remains to be determined. It seems quite apparent, however, that interesting differences must exist between peanuts and Sophora in the metabolism and/or enzymology of 4-substituted glutamic acids and elucidation of such differences could yield

†Transamination of synthetically-prepared DL-OMG showed a biphasic rate of NADH oxidation; after $50 \%$ reaction, the rate decreased to $10 \%$ of the initial rate. The product after $50 \%$ reaction was exclusively erythro-4-Mglu; after completion of the reaction, both isomers were present in equal amounts.
Table 2. Levels of 2-oxo acids in 28-day Sophora japonica seedlings

\begin{tabular}{|c|c|c|c|}
\hline Acid & $\begin{array}{c}\text { Elution } \\
\text { time } \\
\text { (min) }\end{array}$ & Leaf & Root \\
\hline Unknown & 1.89 & 6.70 & 0 \\
\hline 2-Oxoglutarate & 3.35 & 2.51 & 2.15 \\
\hline OMeG & 3.72 & $\sim 1.90$ & 0 \\
\hline OMG & 3.97 & 35.5 & 1.09 \\
\hline Pyruvate (+ OAA)* & 7.66 & 7.58 & 5.47 \\
\hline
\end{tabular}

Values are expressed as $\mu \mathrm{mol} / \mathrm{g}$ dry wt of tissue. Identity and quantitation of peaks were based on standards of quinoxalinol derivatives of 2-oxo acids prepared as described in the text.

- Oxalacetate decarboxylates to give the identical quinoxalinol as pyruvate in this procedure.

insights into the possible function of these compounds in plants.

\section{EXPERIMENTAI.}

Materials. Pods of Sophora japonica were collected from plants growing on the campus of The University of Michigan. The seeds were washed, mechanically scarified, and hydrated in $\mathrm{H}_{2} \mathrm{O}$ for 2-3 hr. These seeds were then placed on moist fiter paper until the radicle emerged, subsequently planted in pots containing moist vermiculite, and finally placed in a growth chamber with a $16 \mathrm{hr}$ light period and a temperature schedule of $27^{\circ}$ (light) and $22^{\circ}$ (dark). The plants were watered twice weekly with the nutrient solution of ref. [13] supplemented with $10 \mathrm{mM} \mathrm{KNO}$ and $1.7 \mathrm{mM} \mathrm{NH}_{4} \mathrm{H}_{2} \mathrm{PO}_{4}$, and with distilled $\mathrm{H}_{2} \mathrm{O}$ on all other occasions. At various times, seedlings or parts thereof were removed, weighed, and then extracted for $6 \mathrm{hr}$ at room temp. with $\mathrm{H}_{2} \mathrm{O}$ containing $0.5 \%$ toluene [14] after the suspension was initially heated to $\mathrm{ca} 80^{\circ}$ for $15 \mathrm{~min}$ in order to inactivate enzymes. Leaves from mature plants were extracted in the same manner, whereas washed but unscarified seeds were crushed immediately before being extracted.

Solvents for HPLC were obtained from Burdick and Jackson Laboratories (Muskegon, MI), reagents for derivatization and analysis of amino acids were from Pierce Chemical Co. (Rockford, IL). Cellulose TLC plates were purchased from Analtech, Inc. (Newark, DE) and Dowex resins were AR grade from BioRad Laboratories (Richmond, CA). Samples of 4-Mglu and 4-Megln, containing all stereoisomers, were synthesized in our laboratories and their 2-oxo analogues were prepared by oxidative deamination by the procedure of Maitra and Dekket [15].

Fractionation and analysis procedures. A portion of the extracts was first subjected to analysis on the amino acid analyser. The $\mathrm{pH}$ of another portion, containing $\mathrm{ca} \mathrm{2-3} \mu \mathrm{mol}$ of amino acids, was then adjusted to 4.4 and the soln passed through a column $(0.7$ $\times 4 \mathrm{~cm}$ ) of Dowex-1 X8 resin (acetate phase) with 2-3 ml of $\mathrm{H}_{2} \mathrm{O}$. The wash fluid containing the neutral and basic compounds was saved; the acidic amino acids and organic acids were eluted from the resin with $1.0 \mathrm{~N} \mathrm{HCl}$. The eluate was concentrated in vacuo to dryness twice, the residue dissolved in $\mathrm{H}_{2} \mathrm{O}$, the $\mathrm{pH}$ of the mixture adjusted to 2.2 , and this soln then passed through a column $(0.7$ $\times 4 \mathrm{~cm}$ ) of Dowex $-50 \times 8$ resin $\left(\mathrm{H}^{+}\right.$phase) with $2-3 \mathrm{ml}$ of water. The wash fluid was analysed for 2-oxo acids and the acidic amino acids were eluted from the resin with $0.5 \mathrm{~N} \mathrm{NH}_{4} \mathrm{OH}$. The $\mathrm{pH}$ of 
the wash fluid containing the neutral and basic compounds was adjusted to 2.2 and this soln passed through a similar column of Dowex-50 resin. Now the wash fluid was discarded while the adsorbed amino acids were eluted with $1.0 \mathrm{NNH}_{4} \mathrm{OH}$. The eluate was concentrated to dryness in vacuo several times and the final residue dissolved in a small vol. of water. This fractionation procedure was used to avoid possible hydrolysis of the amino acid amides by exposure to extremes of $\mathrm{pH}$ and provided quantitative recovery of all amino acids except arginine. Portions of the neutral amino acid fraction were hydrolysed in $6 \mathrm{~N} \mathrm{HCl}$ at $110^{\circ}$ for $16 \mathrm{hr}$ and the acidic amino acids so released were again fractionated on a column of Dowex-1 resin as before.

Amino acid analyses were carried out on a modified Beckman amino acid analyser as previously described [16]. Phenythiocarbamylation and the separation of PTC-amino acids by HPLC were accomplished with the standard pico-tag system [4] except that the $\mathrm{pH}$ of solvent $\mathrm{A}$ was adjusted with HOAc to give the retention times indicated earlier. Waters Associates (Milford, MA) HPLC equipment was used for pico-tag analyses at a pressure of $133 \mathrm{~kg} / \mathrm{cm}^{2}$ and UV detection. A solvent system of $n$ BuOH-propionic acid- $\mathrm{H}_{2} \mathrm{O}(8: 4: 5)$ or of the composition specifically indicated was used for TLC on $250 \mu \mathrm{m}$ Avicel cellulose plates. Thin-layer electrophoresis was performed on the same type of plates in a Pharmacia FBE-3000 apparatus at ca $800 \mathrm{~V}$ and $50 \mathrm{~W}$ for $1.5 \mathrm{hr}$ using the buffer of ref. [6].

Determination of 2-oxo acids. Organic acids in the appropriate fraction were derivatized and analysed by a modification of the method of ref. [17]. Conc $\mathrm{HCl}(0.15 \mathrm{ml})$ and $0.15 \mathrm{ml}$ of an 0 phenylenediamine soln $(50 \mathrm{mM}$ recrystallized o-phenylenediamine in $2 \mathrm{~N} \mathrm{HCl}$ containing $5 \mu$ lof 2 -mercaptoethanol per $\mathrm{ml}$ of soln) were added to $\mathrm{a} 0.6 \mathrm{ml}$ sample containing $\mathrm{ca} 1 \mu \mathrm{mol}$ of 2-oxo acids. After the reaction was allowed to occur for $20 \mathrm{hr}$ at room temp, $0.2 \mathrm{ml}$ of $30 \%$ (w/v) $\mathrm{NH}_{4} \mathrm{Cl}$ soln was added and the mixture then extracted with EtOAc $(4 \mathrm{ml} \times 3)$. The combined EtOAc extracts were dried to a film with a stream of argon. For analysis, the dried samples were dissolved in $0.1 \mathrm{ml} \mathrm{MeOH}$ (HPLC grade), diluted with $0.4 \mathrm{ml} \mathrm{H}_{2} \mathrm{O}$, and $10 \mu \mathrm{l}$ aliquots of these solns were fractionated on an Altex Ultrasphere ODS HPLC column $(0.46 \times 25 \mathrm{~cm})$ with the following solvents and clution system (Waters Associates HPLC equipment, $200 \mathrm{~kg} / \mathrm{cm}^{2}$ pressure, UV detection). Initial conditions consisted of $15 \%$ solvent A $\left(0.15 \mathrm{M} \mathrm{NH}_{4} \mathrm{OAc}\right.$ plus $85 \%$ solvent B (MeCN); linear gradients up to $80 \%$ solvent $A+20 \%$ solvent $B$ in 2 min and then up to $100 \%$ solvent B in $8 \mathrm{~min}$ followed in turn; $100 \%$ solvent B was finally maintained for $10 \mathrm{~min}$. By this procedure, the elution times shown for 2-0xo acids listed in Table 2 were obtained at a flow rate of $1.2 \mathrm{ml} / \mathrm{min}$.

Acknowledgements-This work was supported by Grant PCM8404901 from the National Science Foundation. The help of Dr W. Benninghof in identifying and providing first samples of Sophora japonica is gratefully acknowledged.

\section{REFERENCES}

1. Bell, E. A. (1980) in Encyclopedia of Plant Physiology, New Series 8 (Bell, E.A. and Charlwood, B. V., eds) pp. 403-432. Springer, Berlin.

2. Peterson, P. J. and Fowden, L. (1972) Phytochemistry 11, 663.

3. Rosenthal, G. A. (1980) in Plant Nonprotein Amino and Imino Acids pp. 171-174. Academic Press, New York.

4. Bidlingmeyer, B. A., Cohen, S. A. and Tarum, T. L. (1984) J. Chromatog. 336, 93.

5. Blake, J. and Fowden, L. (1964) Biochem. J. 92, 136.

6. Przybylska, J. and Strong, F. M. (1968) Phytochemistry 7, 471.

7. Virtanen, A. I. and Hietala, P. K. (1955) Acta Chem. Scand. 9 , 12.

8. Dekker, E. E. (1962) in Biachemical Preparations, Vol. 9, pp. 69-74. Wiley, New York.

9. Meister, A. (1965) in Biochemistry of the Amino Acids, Vol. 1, pp. 338-369. Academic Press, New York.

10. Winter, H. C. and Dekker, E. E. (1986) J. Biol. Chem. 261, 11189.

11. Winter, H. C., Powell, G. K. and Dekker, E. E. (1982) Plant Physiol. 69, 41.

12. Fowden, L. (1954) Ann. Bot. London. N. S. 18, 417.

13. Evans, H. J., Koch, B. and Klucas, R. (1972) Meth. Enzymol. 24B, 470.

14. Winter, H. C. and Dekker, E. E. (1984) Plant Physiol. 76, 161.

15. Maitra, U. and Dekker, E. E. (1963) J. Biol. Chem. 238, 3660.

16. Winter, H. C. and Dekker, E. E. (1981) Plant Physiol. 68, 588.

17. Lowe, P. N. and Lowe, A. F. (1985) Biochem. J. 232, 689. 